\title{
US plans next electronics war
}

\section{Washington}

THE US electronics industry has shaken off its lethargy and taken the first strides in a race with Japan and Europe to develop high-definition television (HDTV), a technology that may revolutionize not only television but also the computer and telecommunications industries. Last week, American Telephone and Telegraph (AT\& T) and Zenith Electronics Corporation, the only remaining US-owned television manufacturer, agreed to develop jointly an HDTV system. They have jointly applied to the Defense Advanced Research Projects Agency (DARPA) for support.

HDTV is also becoming a hot issue in Congress; last week saw the introduction of legislation intended to encourage the formation of a government-supported consortium to develop the new technology. Although the United States is late in joining the HDTV race, many in US industry and universities are confident they can leap-frog Europe and Japan.

HDTV, which Japan's National Broad- casting Corporation (NHK) began developing in the early 1970 s, has twice as many lines on the screen as conventional television, and thus offers pictures with greater clarity and resolution. HDTV also has applications in the movie industry, military imaging systems (whence DARPA's interest), still photography, printing, computer graphics and microscopic imaging. And supporters of HDTV talk of linking it with personal computers to create new information media.

If HDTV takes off, it will create a huge market for the semiconductor industry because of its dependence on computer chips. But present versions of HDTV receivers have drawbacks likely to deter consumers. They are heavy, bulky and expensive, while the high quality of the picture is apparent only when the screen is large. This is where US researchers see an opportunity to enter the market.

Zenith, as well as applying to DARPA for $\$ 13$ million to develop HDTV receivers in collaboration with AT\&T, has also applied for $\$ 10$ million to develop a

\section{US lead perceived and envied}

\section{Tokyo}

US INDUSTRY's alarm about Japan's lead in the race to develop high-definition television (HDTV) is unlikely to evoke much sympathy from Japanese companies, which are themselves concerned at the number of fields of high technology in which the United States is dominant.

Recent surveys and the latest white paper (policy document) from the Ministry of International Trade and Industry (MITI) have rather stiffened the determination of Japanese companies to undertake more basic research to help bridge the perceived gap between Japan and the United States.

Surveys serialized last week in Japan's leading economic and industrial newspapers (Nihon Keizai Shinbun and Nihon Sangyo Shinbun) show that Japanese companies believe that in basic research they are ahead of the United States only in the general field of optoelectronics. They believe there is a large gap between Japan and the United States in the life sciences and lesser gaps in the development of computers and new materials.

In an analysis of 47 sub-areas of high technology, Japan believes it has a clear lead over the United States only in highpowered magnets and intelligent robots. In everything else, from high-temperature superconductors through biotechnology to software, the United States is believed to lead. By the year 2000, the United States is seen as still dominant but with
Japan adding leadership in fine ceramics, superconducting devices, carbon materials, ultra-large-scale integrated circuits, new bio-materials, disaster prediction and environmental management.

The really bad news is for Europe, which Japanese companies believe to be well behind the United States in all areas of high-technology research. In 12 of 13 areas of biotechnology, Europe comes ahead of or equal to Japan. But the lead in these areas is expected to vanish by 2000 .

The Nikkei survey complements MITI's most recent white paper. A detailed analysis of the front-line of technological research puts Japan behind the United States not only in the basic research areas explored in the Nikkei survey, but also in areas requiring very-large-scale integration. These include space rockets and satellites, nuclear reactors and civil aircraft.

The MITI white paper seeks success by long-term planning for the generic technology of the next century, by which time the US panic over HDTV may appear misplaced. Although Japan may be in the lead (the first Hi-vision satellite broadcasts are planned for next year and a MITI-led consortium is already developing large flat display screens), HDTV is regarded less as a new and dominating generic technology than as an opportunity for world-wide suppliers of everything from satellites to microchips.

Alun Anderson large-screen version of its "flat tension mask' tubes. It claims these will be cheaper than other display systems.

John Taylor of Zenith says that if the joint venture with AT\&T is fully supported, the companies will be able to put a television on the market for between $\$ 2,500$ and $\$ 3,000$ in $1992-93$. The price of the first Japanese models is about $\$ 12,000$.

William Glenn of the New York Institute of Technology also sees opportunities in the development of flat display screens that can, for example, be hung on a wall. Meanwhile, researchers at the Media Laboratory of the Massachusetts Institute of Technology (MIT) are developing an 'open architecture' computerized HDTV that can be programmed to receive and display signals based on any of the transmission standards being considered in the United States, Europe and Japan.

Budget pressures may limit what can be done. DARPA's programme, announced by the Department of Defense only in December, has only $\$ 30$ million to spend this year, and cannot support all the 80 projects received.

Ironically, although the programme was introduced to spur US initiatives, many of the applicants are foreign-owned companies based in the United States. One is Japan's Sony Corporation, which is asking for the full $\$ 30$ million to develop high-resolution displays and image-processing technology based on the NHK standard.

One possibility is that DARPA could use the funds to establish another government-supported consortium on the lines of SEMATECH, which is given DARPA funds to develop next-generation computer chips. But many in the Pentagon are opposed to DARPA's ventures into the civilian sector, while even the agency's supporters in Congress see the need for new machinery, separate from the defence establishment, for promoting civilian research and development of strategic technology.

Such is the objective of the HDTV bill introduced in the House of Representatives last week by Congressman Don Ritter (Republican, Pennsylvania). The bill would modify antitrust laws to allow US companies to enter joint ventures in the development and manufacture of HDTV. The bill would also offer tax incentives to companies developing HDTV products and would also encourage the administration to provide costsharing finance for a consortium of domestic companies.

But even if the United States manages to leap-frog Japan and Europe in the development of HDTV, will it be able to hold the market? Japanese companies have shown themselves to be remarkably adept at penetrating the US market with highquality low-priced products even when they come from behind. David Swinbanks 